\title{
Influence of the second stage of labor on maternal and neonatal outcomes in vaginal births after caesarean section: a multicenter study in Germany
}

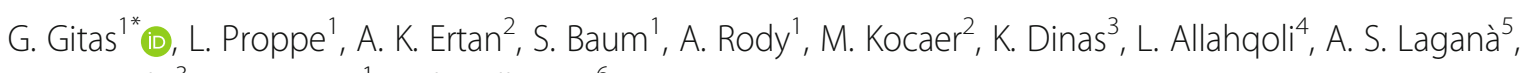

A. Sotiriadis ${ }^{3}$, S. Sommer $^{1}$ and I. Alkatout ${ }^{6}$

\begin{abstract}
Background: The American College of Obstetricians and Gynecologists (ACOG) introduced a new standard of care in 2014, extending the duration of the second stage of labor in order to reduce caesarean delivery (CD) rates and its severe complications. The aim of the present study is to evaluate success rates of trial of labor after caesarean section (TOLAC), as well as maternal and neonatal outcomes after the establishment of the recent guidelines.

Methods: A retrospective study was performed at two large departments in Germany from January 2008 to January 2018. Patients undergoing TOLAC were divided into two groups. Group I (958 patients) was constituted before the establishment of the current guidelines, and Group II (588 patients) after the establishment of the guidelines. A subgroup analysis was performed to compare neonatal outcomes after successful TOLAC and operative vaginal delivery with those after failed TOLAC and secondary CD.
\end{abstract}

Results: The success rate of vaginal births after cesarean section (VBAC) fell from 66.4\% in Group I to 55.8\% in Group II $(p<0.001)$. The median duration of the second stage of labor was statistically significantly longer in Group II than in Group I (79.3 \pm 61.9 vs. $69.3 \pm 58.2 \mathrm{~min})$ for patients without previous vaginal birth. The incidence of operative vaginal delivery decreased from Group I to Group II (9.6\% vs. 6.8\%). The incidence of third- and fourth-degree perineal lacerations, blood loss and emergency CD were similar in the two groups. Concerning the neonatal outcome, our groups did not differ significantly in regard of rates of umbilical artery cord $\mathrm{pH}<7.1(p=0.108)$, the 5 -min Apgar scores below $7(p=0.224)$ and intubation $(p=0.547)$. However, the transfer rates to the neonatal care unit were significantly higher in Group II than in Group I $(p<0.001)$. Neonatal outcomes did not differ significantly in the subgroup analysis.

Conclusion: Extending the second stage of labor does not necessarily result in more vaginal births after TOLAC. Maternal and neonatal outcomes were similar in both groups. Further studies will be needed to evaluate the role of operative vaginal delivery and the duration of the second stage of labor in TOLAC.

Keywords: TOLAC, VBAC, Prolonged second stage, Maternal outcome, Neonatal outcome

\footnotetext{
*Correspondence: g.gitas@gmail.com

'Department of Obstetrics and Gynecology, University Hospital Schleswig Holstein, Campus Luebeck, Ratzeburger Allee 160, Haus A, 23538 Luebeck, Germany

Full list of author information is available at the end of the article
}

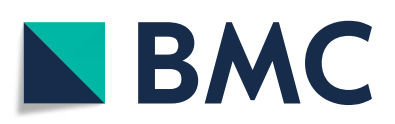

(- The Author(s). 2021 Open Access This article is licensed under a Creative Commons Attribution 4.0 International License, which permits use, sharing, adaptation, distribution and reproduction in any medium or format, as long as you give appropriate credit to the original author(s) and the source, provide a link to the Creative Commons licence, and indicate if changes were made. The images or other third party material in this article are included in the article's Creative Commons licence, unless indicated otherwise in a credit line to the material. If material is not included in the article's Creative Commons licence and your intended use is not permitted by statutory regulation or exceeds the permitted use, you will need to obtain permission directly from the copyright holder. To view a copy of this licence, visit http://creativecommons.org/licenses/by/4.0/. The Creative Commons Public Domain Dedication waiver (http://creativecommons.org/publicdomain/zero/1.0/) applies to the data made available in this article, unless otherwise stated in a credit line to the data. 


\section{Background}

There has been a notable increase in the number of caesarean deliveries (CD) over the last decade throughout the world. In the United States, CD rates rose from $5 \%$ of all deliveries in 1970 to $31.9 \%$ in 2016 [1]. In some countries, a CD is considered necessary or is offered to women who have had previous caesarean sections. This has contributed to the overall increase in CD rates [2]. Thus, the trial of labor after caesarean section (TOLAC) is an essential strategy to reduce CD rates. Vaginal birth after caesarean section (VBAC) is achieved in 65 to $83.3 \%$ of cases [3, 4]. Although VBAC is a safe medical procedure, VBAC rates have declined throughout the world in the last few years. Conversely, the rate of elective repeat caesarean section (ERCS) is on the rise [5]. In the United States, the overall rate of VBAC fell from $24 \%$ in 1996 to $8 \%$ in 2010 , which is a matter of public and professional concern [6]. One reason for this phenomenon may be ambiguous evidence of the risks of VBAC, which causes fear and anxiety in patients [7].

In general, $\mathrm{CD}$ is associated with more severe maternal complications [8] compared to vaginal deliveries. The benefits of vaginal birth, such as rapid maternal recovery, fewer maternal complications in future pregnancies, and a potentially lower risk of childhood diseases (such as allergies, asthma, or obesity) should be taken into account [9]. A number of studies published in recent times have addressed the outcome of TOLAC and yielded variable results. However, VBAC is overall relatively safe for mother and child compared to ERCS [10]. Successful VBACs have been associated with lower overall morbidity rates [11] compared to ERCS. However, a failed VBAC is associated with a higher risk of perinatal and maternal complications compared to ERCS [12].

Based on guidelines published by the ACOG (American College of Obstetricians and Gynecologists) and SMFM (Society for Maternal Fetal Medicine) in 2014 [13], many hospitals throughout the world have introduced a new standard of care concerning the duration of the second stage of labor in order to reduce CD rates. According to these recommendations, the second stage of labor may take an indefinite period of time, provided the delivery progresses well, and maternal and fetal wellbeing are ensured. This statement has been endorsed by other recommendations $[14,15]$ and studies [16]. In contrast, the previous guidelines $[17,18]$ recommended a maximum duration of approximately 1 or $2 \mathrm{~h}$ in multiparous women for the second stage of labor, depending on whether or not a regional anesthesia was performed. The correlation between the duration of the second stage of labor and adverse maternal and neonatal outcomes has been investigated in several studies $[19,20]$.

The purpose of the present study is to investigate the consequences of the most recent ACOG/SMFM guidelines with respect to success rates of TOLAC. We also analyzed maternal and fetal outcomes.

\section{Material and methods}

A retrospective multicenter study was performed at two large departments of obstetrics and gynecology in Germany, including patients with high-risk pregnancies, from January 2008 to January 2018. The study was performed in compliance with the Helsinki declaration, and was approved by the medical ethics committee. The hospital information systems of the academic teaching hospitals of Klinikum Leverkusen and the University Hospital of Luebeck in Germany were used to identify eligible patients. Inclusion criteria were defined as singleton pregnancy, a history of only one previous caesarean delivery with a low transverse incision, a viable fetus in cephalic presentation, patients > 32 weeks of gestation [a vaginal delivery under this gestational age was not favored earlier at the above mentioned our institutions [21-23]], and the intention to deliver by the vaginal route.

A computer-based search yielded 4139 patients with only one previous caesarean section in their medical history. Approximately a half of them had undergone an elective repeat caesarean section. Further exclusion criteria were emergencies before labor, intrauterine growth restriction, fetal anomalies, and multiple gestation. Finally, 1546 patients (607 from Leverkusen and 939 from Luebeck) fulfilled the inclusion criteria (Fig. 1).

Parity, clinical parameters such as age, body mass index (BMI), gestational age, preterm birth, the occurrence of a vaginal birth or VBAC before TOLAC, gestational diabetes, and hypertensive pregnancy-related diseases were analyzed. Maternal surveillance data such as birth analgesia, labor induction, maternal outcomes (estimated blood loss, emergency CD, uterine rupture, third- and fourth-degree perineal tears, episiotomy, postoperative hysterectomies), and fetal outcomes (fetal weight, umbilical artery cord $\mathrm{pH}<7.1$ or $<7.0$, 5-min Apgar scores below 6 or 7, intubation rate, and transfer to neonatal care unit) were analyzed. Oxytocin or prostaglandin were used for the induction of labour. The exact duration of the second stage of labor was registered. Both departments adopted the guidelines published by the ACOG in 2014 concerning the duration of second stage of labor and were universally carried out, Furthermore, the same standards of care were maintained at both institutions. A subgroup analysis was performed to compare neonatal outcomes after VBAC with vaginal operative delivery and failed TOLAC with secondary CD.

The patients were divided into two groups in order to compare VBAC, maternal and fetal outcomes after TOLAC in relation to the duration of the second stage 


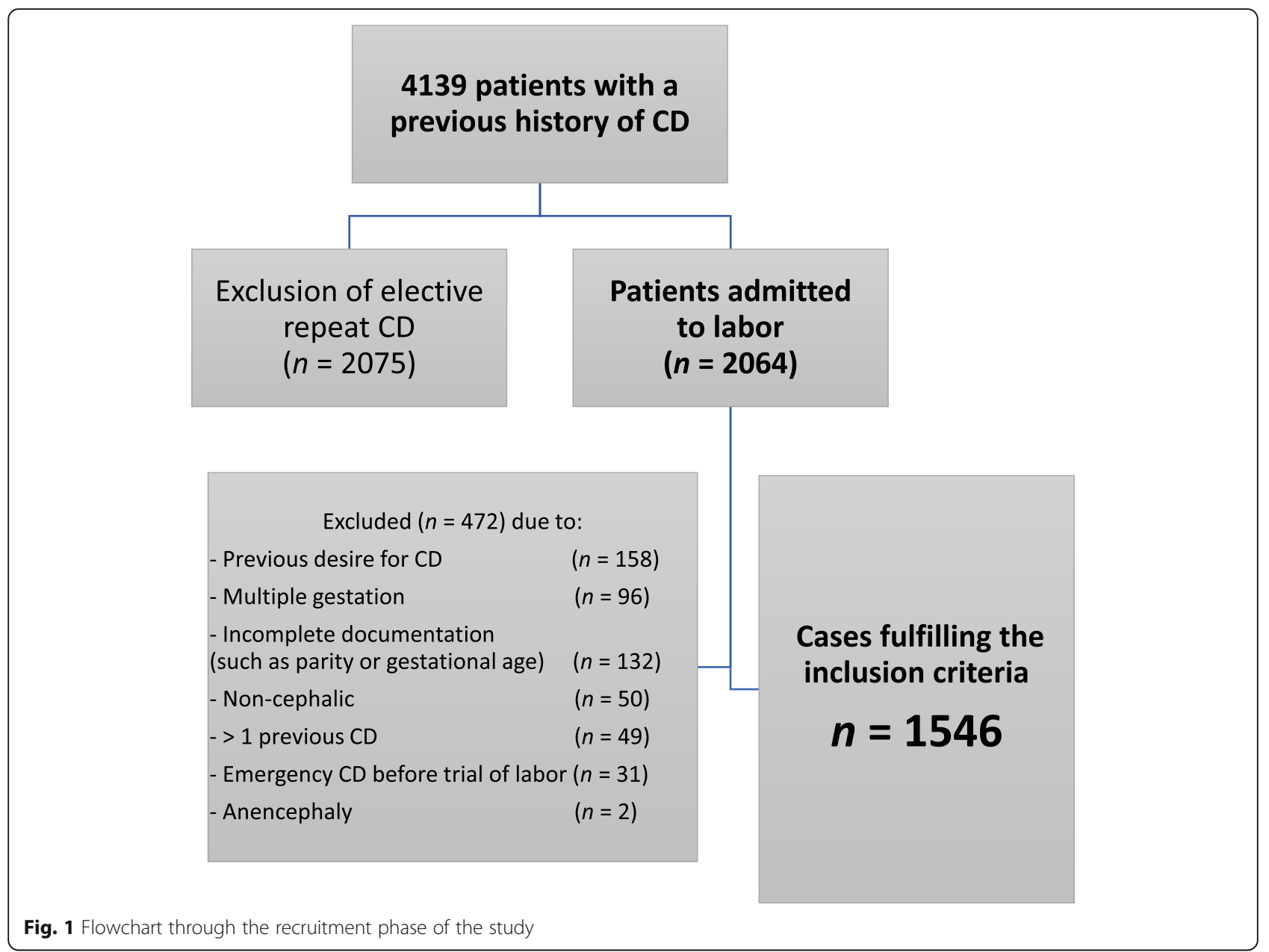

of labor. Group I (958 patients) included deliveries from January 2008 to March 2014 at the University Hospital of Luebeck, and from January 2008 to March 2014 at the academic teaching hospitals of Klinikum Leverkusen (time period I). Deliveries from April 2014 to January 2018 (time period II), constituted Group II (588 patients). The second stage of labor was defined as the period of time from complete dilatation of the cervix to the delivery of the infant. During time period I, a second-stage arrest was established when the second stage persisted for 2 or $3 \mathrm{~h}$, required regional anesthesia in nulliparous women, and a caesarean section had to be considered. In multiparous women, a second-stage arrest was established after 1 or $2 \mathrm{~h}$, coupled with a need for regional anesthesia $[17,18]$. In Group II, based on new standards published in 2012 [15] and 2014 [13], no absolute maximum length of time was defined for the second stage of labor; at least one additional hour elapsed before a second-stage arrest was established. A subgroup analysis was performed to compare neonatal outcomes after VBAC with operative vaginal delivery and failed TOLAC with secondary CD.
Statistical analysis was performed using the SPSS software. Continuous and categorical variables were shown as numbers of patients and percentages. Depending on the scaling and distribution of the variables considered, either a chi-square-test or a Fisher's exact test was performed. $P$-values less than or equal to 0.05 were considered statistically significant.

\section{Results}

Baseline characteristics and maternal surveillance were similar in both groups (958 women in Group I and 588 women in Group II) (Table 1). The median duration of the second stage of labor was longer in Group II (65.4 \pm $60.7 \mathrm{~min})$ than in Group I $(57.4 \pm 56.3 \mathrm{~min})$, but the difference was not statistically significant $(p=0.098)$. However, the median duration of the second stage of labor was significantly longer in patients without previous vaginal delivery $(79.3 \pm 61.9 \mathrm{~min}$ in Group II vs. $69.3 \pm$ $58.2 \mathrm{~min}$ in Group I) $(p=0.045)$.

As shown in Table 2, the rate of successful TOLAC fell from $66.4 \%$ (636/958 patients) in Group I to $55.6 \%$ $(327 / 588)$ in Group II $(p<0.001)$, while CD rates increased 
Table 1 Patient characteristics

\begin{tabular}{|c|c|c|c|c|}
\hline & Group I $(n=958)$ & Group II $(n=588)$ & Total $(n=1564)$ & $p$ \\
\hline Age (years) & $32.5 \pm 5.1$ & $32.5 \pm 4.9$ & $32.5 \pm 5.0$ & 0.702 \\
\hline Parity & $2.4 \pm 0.8$ & $2.3 \pm 0.8$ & $2.4 \pm 0.80$ & 0.055 \\
\hline Gestational age (weeks) & $39.0 \pm 2.1$ & $39.0 \pm 2.1$ & $39.1 \pm 2.1$ & 0.182 \\
\hline $\mathrm{BMI}\left(\mathrm{kg} / \mathrm{m}^{2}\right)$ & $25.4 \pm 5.6$ & $26.0 \pm 6.2$ & $25.7 \pm 5.8$ & 0.197 \\
\hline Previous vaginal birth & $211(28.7 \%)$ & $136(23.6 \%)$ & $347(26.4 \%)$ & 0.036 \\
\hline Prostaglandin used & $264(27.6 \%)$ & $213(36.2 \%)$ & $477(30.9 \%)$ & $<0.001$ \\
\hline Oxytocin used & $410(42.9 \%)$ & $160(27.2 \%)$ & $570(36.9 \%)$ & $<0.001$ \\
\hline Oxytocin and prostaglandin used & $117(12.2 \%)$ & $61(10.4 \%)$ & $178(11.5 \%)$ & 0.271 \\
\hline Gestational diabetes & $110(11.5 \%)$ & $61(10.4 \%)$ & $171(11.1 \%)$ & 0.503 \\
\hline Hypertensive, pregnancy-related disease & $51(5.3 \%)$ & $34(5.8 \%)$ & $85(5.5 \%)$ & 0.699 \\
\hline Birthweight of previous infant delivered by CD (g) & $3049 \pm 811$ & $3059 \pm 816$ & $3052 \pm 811$ & 0.649 \\
\hline Neonatal weight (g) & $3351 \pm 587$ & $3332 \pm 586$ & $3344 \pm 586$ & 0.757 \\
\hline Preterm birth ( $\leq 36+6$ weeks of gestation) & $114(11.9 \%)$ & $72(12.2 \%)$ & $186(12.0 \%)$ & 0.840 \\
\hline Median duration of the second stage of labor (minutes) $(n=789)$ & $57.4 \pm 56.3$ & $65.4 \pm 60.7$ & $61.0 \pm 58.5$ & 0.098 \\
\hline $\begin{array}{l}\text { Median duration of the second stage of labor (minutes) for patients } \\
\text { with previous vaginal birth }(n=227)\end{array}$ & $28.3 \pm 38.3$ & $31.82 \pm 42.3$ & $29.91 \pm 40.1$ & 0.910 \\
\hline $\begin{array}{l}\text { Median duration of the second stage of labor (minutes) for patients } \\
\text { without previous vaginal birth }(n=560)\end{array}$ & $69.3 \pm 58.2$ & $79.3 \pm 61.9$ & $73.8 \pm 60.0$ & 0.045 \\
\hline
\end{tabular}

Table 2 Maternal and neonatal outcome

\begin{tabular}{|c|c|c|c|c|}
\hline & Group I $(n=958)$ & Group II $(n=588)$ & Total $(n=1564)$ & $p$ \\
\hline Successful TOLAC $=$ VBAC & $636(66.4 \%)$ & $327(55.6 \%)$ & $963(62.3 \%)$ & $<0.001$ \\
\hline Vaginal operative delivery & $92(9.6 \%)$ & $40(6.8 \%)$ & $132(8.5 \%)$ & 0.003 \\
\hline Secondary cesarean section & $323(33.7 \%)$ & $257(43.7 \%)$ & $580(37.5 \%)$ & $<0.001$ \\
\hline Episiotomy & $215(22.4 \%)$ & $79(13.4 \%)$ & $294(19.0 \%)$ & $<0.001$ \\
\hline Third- or fourth degree of perineal laceration & $9(0.9 \%)$ & $7(1.2 \%)$ & $16(1.0 \%)$ & 0.636 \\
\hline Blood loss (ml) & $333 \pm 388$ & $331 \pm 204$ & $332 \pm 319$ & 0.095 \\
\hline Emergency CD & $10(1.9 \%)$ & $11(2.6 \%)$ & $21(2.2 \%)$ & 0.449 \\
\hline Uterine rupture & $10(1.0 \%)$ & $10(1.7 \%)$ & $20(1.3 \%)$ & 0.267 \\
\hline Apgar score at 1 min (mean) & $8.46 \pm 1.28$ & $8.50 \pm 1.42$ & $8.48 \pm 1.33$ & 0.017 \\
\hline Apgar score at 5 min (mean) & $9.50 \pm 0.97$ & $9.55 \pm 1.05$ & $9.52 \pm 1.00$ & 0.011 \\
\hline Apgar score at 10 min (mean) & $9.78 \pm 0.77$ & $9.73 \pm 0.95$ & $9.75 \pm 0.85$ & 0.854 \\
\hline Umbilical cord pH & $7.30 \pm 0.09$ & $7.28 \pm 0.09$ & $7.29 \pm 0.09$ & $<0.001$ \\
\hline Base excess & $-3.05 \pm 3.32$ & $-3.04 \pm 3.51$ & $-3.04 \pm 3.41$ & 0.714 \\
\hline Transfer to neonatal care unit & 19 (4.4\%) & $20(11.7 \%)$ & $39 \pm 6.5 \%$ & $<0.001$ \\
\hline Intubation & $7(1.2 \%)$ & $8(1.7 \%)$ & $15 \pm 1.4 \%$ & 0.547 \\
\hline 5-min Apgar score below 6 & $8(0.8 \%)$ & $7(1.2 \%)$ & $15(1.0 \%)$ & 0.489 \\
\hline 5-min Apgar score below 7 & $12(1.3 \%)$ & $12(2.0 \%)$ & $24(1.6 \%)$ & 0.224 \\
\hline $\mathrm{pH}<7.1$ & $10(1.0 \%)$ & $12(2.0 \%)$ & $22(1.4 \%)$ & 0.108 \\
\hline $\mathrm{pH}<7.0$ & $3(0.3 \%)$ & $5(0.9 \%)$ & $8(0.5 \%)$ & 0.166 \\
\hline
\end{tabular}


from 33.7 to $43.7 \%(p<0.001)$. Vacuum-assisted deliveries accounted for $13.7 \%$ of vaginal, and $8.5 \%$ of total deliveries. The incidence of operative vaginal deliveries fell from Group I to Group II (92 to 40 patients in total; $9.2 \%$ vs. $6.8 \% ; p=0.03)$.

With regard to maternal outcome (Table 2), no differences were registered in respect of emergency CD's, uterine rupture, third- and fourth-degree perineal and severe vaginal lacerations, and blood loss by extending the second stage of labor. Two postpartum hysterectomies were performed (one in each group).

With regard to neonatal outcomes, the umbilical artery cord $\mathrm{pH}<7.1$ and the 5-min Apgar scores below 6 or 7 did not have a statistically significant difference between the two groups. Furthermore, they presented similar Apgar scores at $10 \mathrm{~min}(p=0.854)$ and intubation rates $(p=0.547)$. On the other hand, transfer rates to the neonatal care unit were significantly higher in Group II than in Group I $(p<0.001)$ (Table 2).

A subgroup analysis of neonatal outcomes after vaginal operative delivery compared with secondary $\mathrm{CD}$ is shown in Table 3. The 5-min Apgar scores below 6 or 7 did not differ statistical significantly between the two groups. Moreover, intubation rates $(p=0.705)$, rates of transfer to the neonatal care unit $(p=0.371)$, and the frequency of an umbilical cord $\mathrm{pH}<7.1(p=0.731)$ were similar in both groups.

\section{Discussion}

To our knowledge, this is the first study addressing the outcome of TOLAC with reference to the ACOG/ SMFM recommendations [13]. A low CD rate is one of the prime objectives of obstetricians throughout the world [15]. Our data showed that adherence to the guidelines were associated with a significantly longer duration of the second stage of labor in patients without previous vaginal delivery, an unexpected fall in VBAC rates, and a rise in secondary $\mathrm{CD}$ rates after TOLAC.
Moreover, the extension of the second stage of labor was associated with a significant fall in operative vaginal deliveries. Maternal and neonatal outcomes did not differ significantly between groups. Both groups were homogenous in regard of clinical parameters and outcome factors.

A few studies have addressed the effectiveness of the new labor guidelines to prevent primary $\mathrm{CD}$ in all women. The results were controversial. A study from Pennsylvania, USA, revealed a fall in CD rates from 26.9 to $18.8 \%$ in nulliparous patients after the new labor guidelines [24]. Zipori et al. included multiparous and nulliparous women in their analysis, and registered a decrease in CD rates from 23.3 to $15.7 \%$ [25]. By contrast, a study comprising 7845 patients [26] indicated that CD rates were not reduced after application of the new labor guidelines (15.8\% vs. $17.7 \%)$. The management of the second stage of labor with the aim of preventing primary $\mathrm{CD}$ is apparently still a debated issue.

Our results were similar to the observational data obtained from the OptiBIRTH randomized trial [27]: 790 patients undergoing TOLAC from Ireland, Italy, and Germany were analyzed. Patients with a shorter duration of labor had more successful VBAC compared to those with a longer duration of labor. The first and second stage of labor in the OptiBIRTH trial was 4.68 vs. $7.83 \mathrm{~h}$ $(p<0.001)$, and 0.70 vs. $2.13 \mathrm{~h}(p<0.001)$, respectively. Moreover, an earlier intrapartum intervention, such as amniotomy, was significantly associated with more VBAC $(3.50 \mathrm{~h}$ vs. $6.08 \mathrm{~h})$. The authors conclude that a shorter duration of labor favors VBAC, and the progression of labor may be assisted by stimulating endogenous uterine contractions. The effectiveness of stimulating endogenous uterine contractions could not be evaluated in the present study because of its retrospective design.

We observed a decrease in the total number of operative vaginal deliveries after the application of the new guidelines. This might have been due to the different

Table 3 Neonatal outcome of vaginal operative delivery (VOD) in comparison with secondary caesarean section

\begin{tabular}{|c|c|c|c|c|}
\hline & $\operatorname{VOD}(n=135)$ & Secondary CD $(n=577)$ & Total $(n=712)$ & $p$ \\
\hline Apgar at 1 min (mean) & $7.87 \pm 1.59$ & $8.13 \pm 1.68$ & $8.08 \pm 1.66$ & 0.002 \\
\hline Apgar at 5 min (mean) & $9.27 \pm 1.01$ & $9.24 \pm 1.20$ & $9.25 \pm 1.16$ & 0.904 \\
\hline Apgar at 10 min (mean) & $9.65 \pm 0.67$ & $9.60 \pm 0.91$ & $9.60 \pm 0.88$ & 0.805 \\
\hline $\mathrm{pH}$ & $7.23 \pm 0.10$ & $7.31 \pm 0.10$ & $7.29 \pm 0.10$ & $<0.001$ \\
\hline $\mathrm{pH}<7.1$ & $3(4.5 \%)$ & $14(3.8 \%)$ & $17(3.9 \%)$ & 0.731 \\
\hline 5-min Apgar score below 6 & $1(0.8 \%)$ & $10(1.7 \%)$ & $11(1.5 \%)$ & 0.699 \\
\hline 5-min Apgar score below 7 & $3(2.3 \%)$ & $17(2.9 \%)$ & $20(2.8 \%)$ & 1.000 \\
\hline Base excess & $-5.41 \pm 3.51$ & $-2.35 \pm 3.89$ & $-2.81 \pm 3.99$ & $<0.001$ \\
\hline Transfer to neonatal care unit & $7(10.6 \%)$ & $15(7.2 \%)$ & $22(8.0 \%)$ & 0.371 \\
\hline Intubation & $1(1.2 \%)$ & $12(2.9 \%)$ & $13(2.6 \%)$ & 0.705 \\
\hline
\end{tabular}

VOD vaginal operative delivery, $C D$ cesarean section 
approaches towards labor. With the aim of achieving delivery at the latest $2 \mathrm{~h}$ after full cervical dilatation, obstetricians may lead women actively through labor, whereas a longer second stage of labor might favor protraction and reduce uterine rupture rates. Additionally, a prolongation of the second stage may cause maternal exhaustion and favor secondary caesarean section rather than operative vaginal delivery. These circumstances may also cause fetal distress and thus contribute to a higher rate of secondary $\mathrm{CD}$. Unfortunately, we could not address the success rate of vacuum birth in the two groups, which could help us to better interpretate our finding. It is not clear if the physicians performed failed or less vacuum births if the second stage was already long. However, according to our experience, a failed vacuum birth is a rare case. Further research is needed to enlighten this field.

The safety and effectiveness of operative vaginal delivery in relation to the outcome and success of TOLAC were analyzed by Krizman et al. in 1837 patients [28]. Success rates of vaginal operative delivery in TOLAC were high (forceps 90.4\%; vacuum 92.6\%), and neonatal morbidity rates were similar to those for repeat cesarean delivery. With regard to overall morbidity the authors conclude that, in order to avoid secondary CD, TOLAC should be offered to all women with no apparent contraindications for vaginal delivery, and operative vaginal delivery might be considered more often than considered previously in these patients. Our study revealed that, after the establishment of the new guidelines, the number of operative vaginal deliveries fell from 9.2 to $6.8 \%$ and the number of secondary CD increased. These data confirm the conclusions of the above-mentioned study. Additionally, according to our subgroup analysis, operative vaginal delivery has similar neonatal outcome with the secondary CD. Analytically, the incidence of postpartum acidosis $(\mathrm{pH}<7.1)$ were similar in our subgroups ( $4.5 \%$ vs $3.8 \%$ ) but as expected, significant higher as by our main groups (1.0\% Group I vs. $2.0 \%$ Group II). Furthermore, parameters which may be associated to long-term neonatal outcome, such as 5-min Apgar scores below 6 or 7 or Apgar scores at $10 \mathrm{~min}$, did not differ statistical significantly between the two groups. Thus, if we take in considerations the negative maternal effects of CD [29], operative vaginal delivery should be preferred, when possible.

In a retrospective investigation performed in 2019, Miller et al. [30] concluded that an operative intervention might be considered after a two-hour duration of the second stage of labor without epidural anesthesia, a three-hour duration with epidural anesthesia, and a onehour duration or less in women with a previous vaginal delivery, for those undergoing TOLAC. These measures are in accordance with former guidelines. According to the new guidelines $[13,15]$, the duration of the second stage of labor with and without epidural anesthesia could be at least 4 and $3 \mathrm{~h}$, respectively. Zhang et al. [22] used an interval-censored regression to analyze labor curves and suggested that the 95th percentiles of the second stage of labor in nulliparous women were 3.6 and $2.8 \mathrm{~h}$ with and with without epidural anesthesia. However, only low-risk women were included in the investigation. Labor curves for high-risk women, such as those undergoing TOLAC, have not been thoroughly examined yet. As Zheng et al. suggested, the ideal time for the second stage of labor would differ by populations and may be shorter for patients undergoing TOLAC [31].

After application of the new guidelines, we observed a slight but not statistically significant increase in thirdand fourth-degree perineal lacerations from 0.9 to $1.2 \%$. Risk factors for third- and fourth-degree perineal lacerations [32], such as the mother's ethnicity and infants large for their gestational age, were comparable in both groups. Furthermore, as the frequency of vaginal operative deliveries decreased after the establishment of the new guidelines, a reduction in third- and fourth-degree perineal lacerations could be expected. In a study comprising 19,831 patients, Zipori et al. [25] registered an increase in third- and fourth-degree perineal lacerations from 1 to $1.3 \%$ after application of the new labor guidelines. Third- and fourth-degree perineal lacerations exert a significant impact on the patients' quality of life in terms of higher rates of dyspareunia, wound breakdown and infection, urinary incontinence, and postpartum depression secondary to perineal pain [33, 34].

Similar to maternal morbidity, neonatal outcomes did not differ markedly between Groups I and II in the present study. The incidence of postpartum acidosis $(\mathrm{pH}<7.1)$ or severe metabolic acidosis $(\mathrm{pH}<7.0)$ were similar in both groups. Further essential parameters, such as the 5-min Apgar scores below 6 or 7 or Apgar scores at $10 \mathrm{~min}$, did not differ statistical significantly between the two groups. In our study, the proportion of 5-min Apgar scores below 7 (1.3\% in Group I and 2.0\% in Group II) were higher than the medial rate reported in the literature (less than 1\%) [35], which could be expected due to our high-risk collective. On the other hand, transfer rates to the neonatal care unit were significantly higher in Group II than in Group I (11.7\% vs. $4.4 \%$ ). Unfortunately, we could not find a reasonable explanation about this difference, which may be associated with the development of a more safe and accurate neonatal examination and surveillance in the last years, an issue which seems to be multifactorial [36]. Further research is needed in order to enlighten this field.

Sepsis and infection rates were not included in this analysis because of the small number of cases. Moreover, it was not possible to analyze the rate of preeclampsia because of a change in diagnostic criteria during the study 
period. Two recent studies $[37,38]$ investigating morbidity and $C D$ prevention rates after application of the new labor guidelines showed no association between the duration of the second stage of labor and maternal or neonatal morbidity. However, some studies revealed increased rates of chorioamnionitis, sepsis, uterine atony, and third- or fourth-degree perineal lacerations after a prolonged second stage of labor [16, 39]. A prolonged second stage with the aim of reducing $\mathrm{CD}$ rates may be associated with higher maternal and neonatal morbidity rates. Thus, this strategy is still a controversially discussed issue.

To our knowledge, the current study is the first to analyze the outcome of patients undergoing TOLAC before and after the new recommendations of the ACOG/SMFM [13], especially with regard to the duration of the second stage of labor. Statistical bias was reduced by the fact that the present investigation was a multicenter study in a large population with homogenous groups. However, the limitations of the study are worthy of mention. The retrospective design called for a careful interpretation of the results. Factors such as physician's or midwife's experience and preferences were not assessed, and might have accounted for the results. Furthermore, the retrospective design of the present study provided a relatively large study population, but was limited by the documentation performed during the deliveries. Moreover, the size of the study didn't not allow us to perform a multivariate regression analysis, which may negatively influence our results and increase the risk of statistical bias. On the other hand, after the establishment of the new guidelines, it will be difficult to perform a prospective study with sufficient numbers of patients.

\section{Conclusions}

The present study provides new data about the outcome of TOLAC after the establishment of the ACOG/SMFM recommendations concerning the duration of the second stage of labor. Notably, the investigation revealed that a prolonged second stage of labor does not necessarily lead to more vaginal births after TOLAC. We also observed a reduction in vaginal operative deliveries. Further studies will have to evaluate the role of the second stage of labor on CD rates, especially in TOLAC. Several thousands of patients will be needed to obtain statistically robust data concerning severe maternal and neonatal complications. Moreover, prospective studies will be likely to provide valuable data on the care of women with VBAC. Women undergoing TOLAC are known to be subject to a higher risk of obstetric complications; normal labor curves have not been assessed for them. Based on the existing data, we conclude that women who have no contraindications for vaginal delivery should be encouraged to undergo TOLAC after a careful medical assessment. This should be accompanied by careful monitoring at well-equipped centers with facilities for immediate operative procedures.

\section{Abbreviations}

ACOG: American College of Obstetricians and Gynecologists; CD: Caesarean delivery; ERCS: Elective repeat caesarean section; SMFM: Society for Maternal Fetal Medicine; TOLAC: Trial of labor after caesarean section; VBAC: Vaginal births after cesarean section

\section{Acknowledgments}

Not applicable. All contributors meet the criteria for authorship. No further contribution was provided.

\section{Submission}

The work described herein has not been published earlier and is not under consideration for publication anywhere else.

\section{Authors' contributions}

Protocol/project development: GG, PL, Al, EAK, RA, DK, SA, AL, LAS. Data collection or management: GG, PL, BS. KM, SS, EAK, RA. Data analysis: GG, PL, Al, KM, SS. Manuscript writing/editing: GG, PL, Al, RA, BS, EAK, DK, SA, AL, LAS, SS, KM. All authors read and approved the final manuscript.

Funding

Open Access funding enabled and organized by Projekt DEAL.

\section{Availability of data and materials}

The datasets used and analyzed during the current study are available from the corresponding author on reasonable request.

\section{Declarations}

Ethics approval and consent to participate

Approval was obtained from the ethics committee of the Medical Faculty of the academic teaching hospitals of Leverkusen and University at Luebeck (Approval number 19-285A). Administrative permissions and/or licenses were acquired by our team to access the data used in our research. The investigation was performed in accordance with the Declaration of Helsinki.

Consent for publication

Not applicable.

\section{Competing interests}

The authors declare that they have no competing interests.

\section{Author details}

'Department of Obstetrics and Gynecology, University Hospital Schleswig Holstein, Campus Luebeck, Ratzeburger Allee 160, Haus A, 23538 Luebeck, Germany. ${ }^{2}$ Department of Obstetrics and Gynecology, Leverkusen Municipal Hospital, Leverkusen 51375, Germany. ${ }^{3}$ Second Department of Obstetrics and Gynecology, Medical School, Aristotle University of Thessaloniki,

Konstaninoupoleos 49, Thessaloniki 546 42, Greece. ${ }^{4}$ School of Public Health, Iran University of Medical Sciences (IUMS), Tehran 14535, Iran. ${ }^{5}$ Department of Obstetrics and Gynecology, Filippo Del Ponte Hospital, University of Insubria, Varese, Italy. ${ }^{6}$ Department of Obstetrics and Gynecology, University Hospital Schleswig Holstein, Campus Kiel, Kiel, Germany.

Received: 10 October 2020 Accepted: 20 April 2021

Published online: 04 May 2021

\section{References}

1. Martin JA, Hamilton BE, Osterman MJK. Births in the United States, 2017. NCHS Data Brief. 2018;(318):1-8.

2. Cheng YW, Eden KB, Marshall N, Pereira L, Caughey AB, Guise JM. Delivery after prior cesarean: maternal morbidity and mortality. Clin Perinatol. 2011; 38(2):297-309. https://doi.org/10.1016/j.clp.2011.03.012.

3. Kiwan R, Al Qahtani N. Outcome of vaginal birth after cesarean section: a retrospective comparative analysis of spontaneous versus induced labor in women with one previous cesarean section. Ann Afr Med. 2018;17(3):14550. https://doi.org/10.4103/aam.aam_54_17.

4. Haumonte JB, Raylet M, Christophe M, Mauviel F, Bertrand A, Desbriere R, et al. French validation and adaptation of the Grobman nomogram for prediction of vaginal birth after cesarean delivery. J Gynecol Obstet Hum Reprod. 2018;47(3):127-31. https://doi.org/10.1016/j.jogoh.2017.12.002. 
5. Knight HE, Gurol-Urganci I, van der Meulen JH, Mahmood TA, Richmond $\mathrm{DH}$, Dougall A, et al. Vaginal birth after caesarean section: a cohort study investigating factors associated with its uptake and success. BJOG. 2014; 121(2):183-92. https://doi.org/10.1111/1471-0528.12508.

6. MacDorman M, Declercq E, Menacker F. Recent trends and patterns in cesarean and vaginal birth after cesarean (VBAC) deliveries in the United States. Clin Perinatol. 2011;38(2):179-92. https://doi.org/10.1016/j. clp.2011.03.007

7. Spong CY. To VBAC or not to VBAC. PLoS Med. 2012;9(3):e1001191. https:// doi.org/10.1371/journal.pmed.1001191.

8. Ye J, Betran AP, Guerrero Vela M, Souza JP, Zhang J. Searching for the optimal rate of medically necessary cesarean delivery. Birth. 2014;41(3):23744. https://doi.org/10.1111/birt.12104.

9. Okada H, Kuhn C, Feillet H, Bach JF. The 'hygiene hypothesis' for autoimmune and allergic diseases: an update. Clin Exp Immunol. 2010; 160(1):1-9. https://doi.org/10.1111/j.1365-2249.2010.04139.x.

10. Dodd JM, Crowther CA, Huertas E, Guise J, Horey D. Planned elective repeat caesarean section versus planned vaginal birth for women with a previous caesarean birth. Cochrane Database of Systematic Reviews. 2013;(12): CD004224. https://doi.org/10.1002/14651858.CD004224.pub3.

11. Landon MB, Hauth JC, Leveno KJ, Spong CY, Leindecker S, Varner MW, et al. Maternal and perinatal outcomes associated with a trial of labor after prior cesarean delivery. N Engl J Med. 2004;351(25):2581-9. https://doi.org/10.1 056/NEJMoa040405

12. McMahon MJ, Luther ER, Bowes WA Jr, Olshan AF. Comparison of a trial of labor with an elective second cesarean section. N Engl J Med. 1996;335(10): 689-95. https://doi.org/10.1056/NEJM199609053351001.

13. American College of $\mathrm{O}$, Gynecologists, Society for Maternal-Fetal M, Caughey AB, Cahill AG, Guise JM, et al. Safe prevention of the primary cesarean delivery. Am J Obstet Gynecol. 2014;210(3):179-93.

14. Caughey $A B$. Is there an upper time limit for the management of the second stage of labor? Am J Obstet Gynecol. 2009;201(4):337-8. https://doi. org/10.1016/j.ajog.2009.08.001.

15. Spong CY, Berghella V, Wenstrom KD, Mercer BM, Saade GR. Preventing the first cesarean delivery: summary of a joint Eunice Kennedy Shriver National Institute of Child Health and Human Development, Society for MaternalFetal Medicine, and American College of Obstetricians and Gynecologists Workshop. Obstet Gynecol. 2012;120(5):1181-93. https://doi.org/10.1097/A OG.0b013e3182704880

16. Rouse DJ, Weiner SJ, Bloom SL, Varner MW, Spong CY, Ramin SM, et al. Second-stage labor duration in nulliparous women: relationship to maternal and perinatal outcomes. Am J Obstet Gynecol. 2009;201(4):357 e1-7.

17. Friedman EA. Primigravid labor; a graphicostatistical analysis. Obstet Gynecol. 1955;6(6):567-89. https://doi.org/10.1097/00006250-195512000-00001.

18. American College of O, Gynecology Committee on Practice B-O. ACOG practice bulletin number 49, December 2003: dystocia and augmentation of labor. Obstet Gynecol. 2003;102(6):1445-54. https://doi.org/10.1016/j. obstetgynecol.2003.10.011.

19. Zhang J, Troendle J, Grantz KL, Reddy UM. Statistical aspects of modeling the labor curve. Am J Obstet Gynecol. 2015;212(6):750 e1-4.

20. Cohen WR, Friedman EA. Misguided guidelines for managing labor. Am J Obstet Gynecol. 2015;212(6):753 e1-3.

21. Fischer $T$, Mortl M, Reif $P$, Kiss $H$, Lang $U$, Austrian Society for $G$, et al. Statement by the OEGGG with review of the literature on the mode of delivery of premature infants at the limit of viability. Geburtshilfe Frauenheilkd. 2018;78(12):1212-6. https://doi.org/10.1055/a-0669-1480.

22. Zhang J, Landy HJ, Branch DW, Burkman R, Haberman S, Gregory KD, et al. Contemporary patterns of spontaneous labor with normal neonatal outcomes. Obstet Gynecol. 2010;116(6):1281-7. https://doi.org/10.1097/AOG. 0b013e3181fdef6e.

23. Gravenhorst JB, Schreuder AM, Veen S, Brand R, Verloove-Vanhorick SP, Verweij RA, et al. Breech delivery in very preterm and very low birthweight infants in The Netherlands. Br J Obstet Gynaecol. 1993;100(5):411-5. https:// doi.org/10.1111/j.1471-0528.1993.tb15263.x.

24. Wilson-Leedy JG, DiSilvestro AJ, Repke JT, Pauli JM. Reduction in the cesarean delivery rate after obstetric care consensus quideline implementation. Obstet Gynecol. 2016;128(1):145-52. https://doi.org/10. 097/AOG.0000000000001488.

25. Zipori Y, Grunwald O, Ginsberg Y, Beloosesky R, Weiner Z. The impact of extending the second stage of labor to prevent primary cesarean delivery on maternal and neonatal outcomes. Am J Obstet Gynecol. 2019:220(2):191 e1-7.

26. Rosenbloom II, Stout MJ, Tuuli MG, Woolfolk CL, Lopez JD, Macones GA, et al. New labor management guidelines and changes in cesarean delivery patterns. Am J Obstet Gynecol. 2017;217(6):689 e1-8.

27. Grylka-Baeschlin S, Clarke M, Begley C, Daly D, Healy P, Nicoletti J, et al. Labour characteristics of women achieving successful vaginal birth after caesarean section in three European countries. Midwifery. 2019;74:36-43. https://doi.org/10.1016/j.midw.2019.03.013.

28. Krizman E, Grzebielski P, Antony KM, Sampene E, Shanahan M, Iruretagoyena $\mathrm{Jl}$, et al. Operative vaginal delivery is a safe option in women undergoing a trial of labor after cesarean. AJP Rep. 2019;9(2):e190-e4. https://doi.org/10.1055/s-0039-1692482.

29. Norhayati MN, Nik Hazlina NH, Aniza AA, Sulaiman Z. Factors associated with severe maternal morbidity in Kelantan, Malaysia: a comparative crosssectional study. BMC Pregnancy Childbirth. 2016;16(1):185. https://doi.org/1 0.1186/s12884-016-0980-2.

30. Miller N, Pelleg M, Hag-Yahia N, Daykan Y, Pasternak Y, Biron-Shental T. Labor progression of women attempting vaginal birth after previous cesarean delivery with or without epidural analgesia. Arch Gynecol Obstet. 2019;299(1):129-34. https://doi.org/10.1007/s00404-018-4956-5.

31. Zheng L, Zhang Q, Liao Q, Chen R, Xu R, Han Q, et al. Labor patterns in Chinese women in Fuzhou attempting vaginal birth after previous cesarean delivery: a retrospective cohort study. J Int Med Res. 2019;47(12):6091-9. https://doi.org/10.1177/0300060519884145.

32. Wilson AN, Homer CSE. Third- and fourth-degree tears: a review of the current evidence for prevention and management. Aust N Z J Obstet Gynaecol. 2020;60(2):175-82. https://doi.org/10.1111/ajo.13127.

33. Rathfisch G, Dikencik BK, Kizilkaya Beji N, Comert N, Tekirdag Al, Kadioglu A. Effects of perineal trauma on postpartum sexual function. J Adv Nurs. 2010; 66(12):2640-9. https://doi.org/10.1111/j.1365-2648.2010.05428.x.

34. Fenner DE, Genberg B, Brahma P, Marek L, DeLancey JO. Fecal and urinary incontinence after vaginal delivery with anal sphincter disruption in an obstetrics unit in the United States. Am J Obstet Gynecol. 2003;189(6):15439; discussion 9-50. https://doi.org/10.1016/j.ajog.2003.09.030.

35. Ehrenstein V, Pedersen L, Grijota M, Nielsen GL, Rothman KJ, Sorensen HT. Association of Apgar score at five minutes with long-term neurologic disability and cognitive function in a prevalence study of Danish conscripts. BMC Pregnancy Childbirth. 2009;9(1):14. https://doi. org/10.1186/1471-2393-9-14

36. de Jongh BE, Locke R, Paul DA, Hoffman M. The differential effects of maternal age, race/ethnicity and insurance on neonatal intensive care unit admission rates. BMC Pregnancy Childbirth. 2012;12(1):97. https://doi.org/1 0.1186/1471-2393-12-97.

37. Gimovsky AC, Berghella V. Randomized controlled trial of prolonged second stage: extending the time limit vs usual guidelines. Am J Obstet Gynecol. 2016;214(3):361 e1-6.

38. Thuillier C, Roy S, Peyronnet V, Quibel T, Nlandu A, Rozenberg P. Impact of recommended changes in labor management for prevention of the primary cesarean delivery. Am J Obstet Gynecol. 2018;218(3):341 e1-9.

39. Laughon SK, Berghella V, Reddy UM, Sundaram R, Lu Z, Hoffman MK. Neonatal and maternal outcomes with prolonged second stage of labor. Obstet Gynecol. 2014;124(1):57-67. https://doi.org/10.1097/AOG. 0000000000000278 .

\section{Publisher's Note}

Springer Nature remains neutral with regard to jurisdictional claims in published maps and institutional affiliations. 